\title{
Los registros de patrimonio inmaterial, una herramienta para la conservación de las reservas de la biosfera
}

Fruto de un proyecto para promover el patrimonio inmaterial de las reservas de la biosfera de España como parte esencial para la conservación del patrimonio natural, a finales de 2016 el Organismo Autónomo Parques Nacionales publicaba el Catálogo abierto del patrimonio inmaterial de las Reservas de la Biosfera españolas, elaborado por la Fundación Fernando González Bernáldez y EUROPARC-España. El Catálogo incorpora un total de 101 fichas de recursos del patrimonio cultural inmaterial, incluyendo recursos de todas las reservas de la biosfera de España declaradas hasta 2015.

Marta Múgica de la Guerra, Javier Puertas Blázquez | EUROPARC-España

URL de la contribución <www.iaph.es/revistaph/index.php/revistaph/article/view/4119>

Las áreas protegidas son la herramienta más ensayada para la conservación del patrimonio natural y de la diversidad biológica, aunque se puede afirmar que su contribución va mucho más allá, incluyendo también bienes y servicios culturales tangibles e inmateriales. La definición de la Unión Internacional para la Conservación de la Naturaleza (UICN) es bastante clarificadora en cuanto a la aportación de las áreas protegidas a la conservación del patrimonio en un sentido amplio, apuntando que la misión de las áreas protegidas no se limita a conservar la naturaleza sino también "los valores culturales asociados".

Determinados usos del territorio y los conocimientos tradicionales ligados al manejo de prácticas agrosilvopastorales han sido reconocidos como factores fundamentales para la conservación de la biodiversidad y la agrodiversidad, y por tanto las distintas tipologías de áreas protegidas deben incorporar estos aspectos como parte esencial de su gestión. El caso particular de la Reserva de la Biosfera, una figura internacional avalada por la UNESCO, tiene su origen precisamente en el reconocimiento del complejo pero necesario equilibrio entre la conservación de la naturaleza y el desarrollo sostenible donde la conservación del patrimonio natural puede llegar a estar íntimamente ligada al mantenimiento de determinadas prácticas sociales y culturales.

Podemos decir que en todas las áreas protegidas existen, e incluso pueden llegar a ser seña de identidad de los territorios, otros valores culturales como los de tipo histórico (hechos o eventos históricos relevantes), lingüístico (cuentos y leyendas, dialectos), artístico (danzas, música tradicional, fotografía de naturaleza), social (oficios tradicionales, gastronomía), religioso (romerías y peregrinaciones) o espiritual (ermitas, fuentes). A estos valores se les reconoce un gran interés estratégico por el carácter identitario que suponen y, por tanto, por la vinculación que favorecen entre las personas (locales y visitantes) y los objetivos de gestión del lugar. Tienen además un gran valor desde la perspectiva de la comunicación.

Desde el punto de vista de la gestión de las áreas protegidas, y en particular considerando las reservas de la biosfera como lugares donde se explicitan objetivos de conservación y desarrollo sostenible, cabe subrayar que su misión no se limita a la conservación del patrimonio natural, sino que la gestión debe incorporar la salvaguarda de los valores culturales asociados.

El Organismo Autónomo Parques Nacionales (OAPN), organismo responsable del impulso de la Red Española de Reservas de la Biosfera, desarrolla iniciativas de interés para el conjunto de estos espacios. Entre otras, se consensuó la elaboración de un catálogo abierto del patrimonio inmaterial de las reservas de la biosfera españolas, con el objetivo último de poner en valor dichos recursos patrimoniales. La Fundación Fernando 
González Bernáldez, a través de la Oficina Técnica de EUROPARC-España y en estrecha colaboración con el OAPN y los gestores de las reservas de la biosfera, asumió este encargo. Como experiencia previa fue fundamental lo aprendido en el proceso de elaboración del manual El patrimonio inmaterial: valores culturales $y$ espirituales. Manual para su incorporación en las áreas protegidas promovido por EUROPARC-España.

Para el diseño de la ficha del catálogo se han tenido en cuenta los principales ámbitos del patrimonio inmaterial considerados en el Convención para la Salvaguardia del Patrimonio Cultural Inmaterial de UNESCO (2003): tradiciones y expresiones orales, incluido el idioma como vehículo del patrimonio cultural inmaterial; artes del espectáculo, como la música tradicional, la danza y el teatro; usos sociales, rituales y actos festivos; conocimientos y usos relacionados con la naturaleza y el universo; y técnicas artesanales tradicionales.

En la primera entrega del Catálogo abierto del patrimonio inmaterial de las reservas de la biosfera españolas, tras consensuar la aproximación con gestores y técnicos, se ha dado prioridad a los lugares o expresiones de interés cultural, espiritual u otros valores inmateriales, y los usos tradicionales de los recursos naturales y variedades domésticas, en relación a conocimientos y usos relacionados con la naturaleza y el universo; a la artesanía y técnicas arraigadas en el territorio tradicionalmente, dentro de las técnicas artesanales tradicionales; y a las fiestas populares tradicionales de interés turístico, como usos sociales, rituales y actos festivos, en los tres casos dentro de los ámbitos establecidos por UNESCO.

El catálogo en su primera entrega, en 2016, incorpora un total de 101 fichas de recursos del patrimonio cultural inmaterial, con ejemplos del patrimonio cultural inmaterial de todas las reservas de la biosfera de España declaradas hasta 2015.

La prospección realizada ha permitido constatar que las reservas de la biosfera han abordado el tema del patrimonio cultural inmaterial de manera desigual. Mientras que algunas, como sería el caso del Montseny en Cataluña

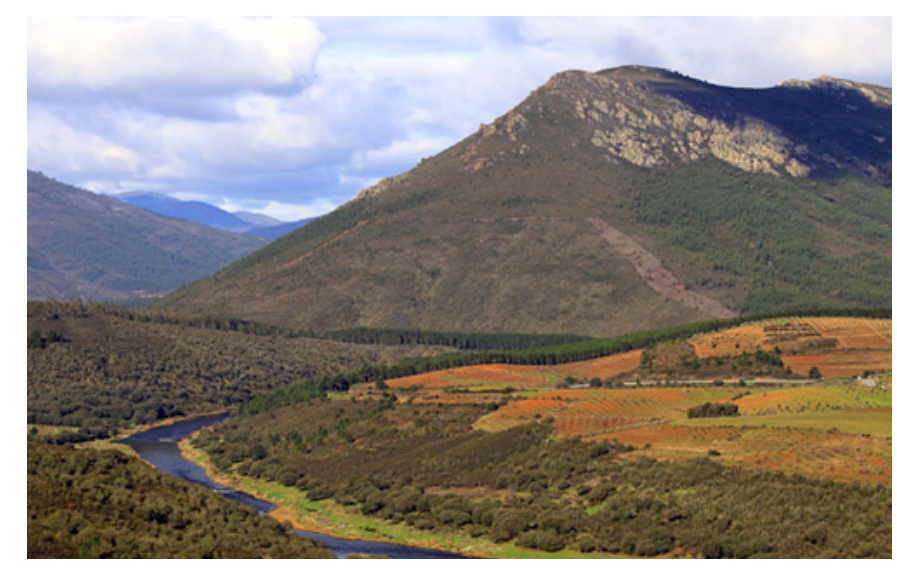

Reserva de la Biosfera: sierra de Francia y Béjar (Castilla y León) | foto Javier Puertas

o sierra de las Nieves en Andalucía, disponen de inventarios más o menos pormenorizados, en otras muchas reservas apenas se ha trabajado en la documentación de su patrimonio cultural inmaterial. En algunos casos el proceso de elaboración del catálogo ha derivado en una reflexión sobre la necesidad de documentar adecuadamente el patrimonio inmaterial, y son varias las reservas de la biosfera que han empezado a trabajar en sus correspondientes catálogos.

En esta primera entrega del catálogo predominan los ámbitos del patrimonio cultural inmaterial referidos a los usos tradicionales de los recursos naturales y las variedades domésticas, los lugares de interés cultural y las fiestas locales. Sólo puntualmente se han documentado recursos patrimoniales relativos a las técnicas artesanales tradicionales. Sería de interés completar el catálogo abierto del patrimonio inmaterial incluyendo en el mismo al menos un recurso patrimonial de cada uno de los ámbitos considerados en la Convención para la Salvaguardia del Patrimonio Cultural Inmaterial de UNESCO.

\section{BIBLIOGRAFÍA}

- MALLARACH, J. M.; COMAS, E.; ARMAS, A. (DE) (2012) El patrimonio inmaterial: valores culturales y espirituales. Manual para su incorporación en las áreas protegidas. Madrid: Fundación Fernando González Bernáldez, 2012 (Serie de manuales EUROPARC-España; 10. Programa de trabajo de las áreas protegidas 2009-2013) 